\title{
Acute leukaemia of ambiguous lineage - a diagnostic dilemma
}

\author{
L V Gooneratne'1, M D M Wijeratne ${ }^{1}$, H D H S Gunasekara², M N Tudawe ${ }^{2}$ \\ (Index words: acute leukaemia, ambiguous, flowcytometry, blasts)
}

\begin{abstract}
Acute leukaemia of ambiguous lineage (ALAL) is a rare form of leukaemia in which morphologic, cytochemical and immuno-phenotypic features of the proliferating blasts lack sufficient evidence to classify them as myeloid or lymphoid in origin or have characteristics of both myeloid and lymphoid cells. We report a 22-year old man presenting with clinical features of an acute lymphoblastic leukaemia but blasts in his blood and bone marrow with morphological features of myeloblasts. His immunophenotyping by flowcytometry showed antigens specific for both myeloid and B-lymphoid lineages. We highlight the importance of correlating clinical features with cellular morphology when diagnosing acute leukaemias, especially when facilities for flowcytometry are not routinely available.
\end{abstract}

\section{Introduction}

Acute leukaemia of ambiguous lineage (ALAL) is a rare form of leukaemia in which morphologic, cytochemical and immuno-phenotypic features of the proliferating blasts lack sufficient evidence to classify them as myeloid or lymphoid in origin or have characteristics of both myeloid and lymphoid cells [1]. They account for less than $4 \%$ of all cases of acute leukaemia, and their prognosis is unfavourable [1]. We report an unusual case of acute leukaemia with clinical features of a lymphoblastic leukaemia (ALL) but blasts with morphological features of myeloblasts. This discrepancy prompted us to immunophenotype the blasts.

\section{Case history}

A 22-year old man presented with fever and sore throat of 2 weeks duration. He had no bleeding manifestations or bone pain. His father had died of a haematological malignancy a few years back. He looked ill, was febrile $\left(38^{\circ} \mathrm{C}\right)$ and pale. He had generalised lymphadenopathy including multiple bilateral cervical nodes, the largest measuring about $3 \mathrm{~cm}$ in diameter. Liver and spleen were palpable $3 \mathrm{~cm}$ below the costal margin. He did not have gum hypertrophy or bone tenderness.
Full blood count and blood picture revealed a normocytic anaemia (haemoglobin $-6.7 \mathrm{~g} / \mathrm{dl}$ ), a total white cell count of $321 \times 10^{9} / 1$ with $90 \%$ blasts and a platelet count of $62 \times 10^{9} / 1$. A provisional diagnosis of ALL was made mainly on clinical grounds.

Bone marrow aspirate was markedly hypercellular with marked reduction in normal haemopoiesis. About $90 \%$ of nucleated marrow cells were blasts, the majority of which had the appearance of myeloblasts (Figure 1a). About 3\% stained positive with sudan black B- a cytochemical marker for myeloblasts (Figure 1b). Cellular morphology favoured a diagnosis of acute myeloid leukaemia (AML)-FAB subtype M1.

As the clinical picture and cellular morphology did not compliment each other peripheral blood was sent for immunophenotyping by flowcytometry to Mumbai, India. The patient was started on oral prednisolone $(1 \mathrm{mg} / \mathrm{kg} /$ day) and allopurinol (300 mg/day) empirically.

Immunophenotyping by flowcytometry (Table 1) revealed that $99 \%$ of blasts expressed the B-lymphoid marker CD19, while $58 \%$ of these blasts co-expressed the myeloid marker CD13. Blasts were negative for T-cell markers. Findings were suggestive of an acute mixed lineage leukaemia. Further testing with cytoplasmic myeloperoxidase (cMPO) and cytoplasmic CD79a (c79a) was recommended to ascertain if this was a biphenotypic leukaemia $(\mathrm{BpL})$, but this could not be done. The patient died during the first course of chemotherapy.

\section{Discussion}

The overall incidence of acute leukaemia worldwide is approximately $4 / 100,000$ population per year, about 70\% being AML. However, the treatment for ALL and AML are different. In addition to AML and ALL, the WHO classification of 1999 describes a rare subtype of acute leukaemia called ALAL, the identification of which is important for risk stratification [3]. ALAL occurs both in children and adults. ALAL is subdivided into undifferentiated acute leukaemia, acute bilineal leukaemia and acute BpL. Acute BpL may have morphologic and

${ }^{1}$ Department of Pathology, Faculty of Medicine, Colombo, Sri Lanka and ${ }^{2}$ Haematology Unit, National Hospital of Sri Lanka.

Correspondence: MT, e-mail <malant@sltnet.lk>. Received 21 May 2008 and accepted 21 January 2009. Competing interests: none declared. 
immunophenotypic characteristics of both myeloid and lymphoid cells or both B and T lineages. Our patient belonged to the latter group. The classification of bilineal and $\mathrm{BpL}$ leukaemias are dependant on the demonstration of lineage specific antigens on the blasts by immunophenotyping. The former is defined by the detection of a dual population of blasts with each population expressing markers of a distinct lineage. The latter is characterised by blasts which co-express myeloid and lymphoid or concurrent B and T lineage antigens. A scoring system (Table 2) proposed by the European Group for the Immunologic Classification of Leukaemia (EGIL) is used for this $[3,4]$. Detected antigens are given a score of 2,1 , or 0.5 depending on the specificity of that particular antigen for myeloid, T-lymphoid, or B-lymphoid lineages [5]. A score of greater than 2 in two lineages (myeloid or Tor B-cells) are referred to as BpL. Although the blasts in our patient demonstrated morphologic and immunophenotypic features of both myeloid and B lymphoid lineages the EGIL score was only 1.0 in each because being cMPO and cCD79a were not performed. ALAL frequently demonstrates an aggressive disease course, with mean survival rates less than those for leukaemias derived from a single-cell lineage [5].

It is important to correlate clinical features with cellular morphology when diagnosing acute leukaemias, especially when facilities for flowcytometry are not routinely available.
Table 1. Immunophenotyping results of the patient's peripheral blood blasts by flowcytometry

\begin{tabular}{lc}
\hline Immunophenotypic markers & $(\%)$ \\
\hline CD45 & 99
\end{tabular}

T-lymphoid markers

CD7 02

CD5 0

CD3 02

B-lymphoid markers

CD10 99

$\mathrm{CD} 22$

CD20 08

CD10/CD19(Co-expression) 99

CD19 99

Myeloid markers

CD13 58

CD33 23

CD117 0

Non-lineage specific markers

CD34 43

HLADR 98

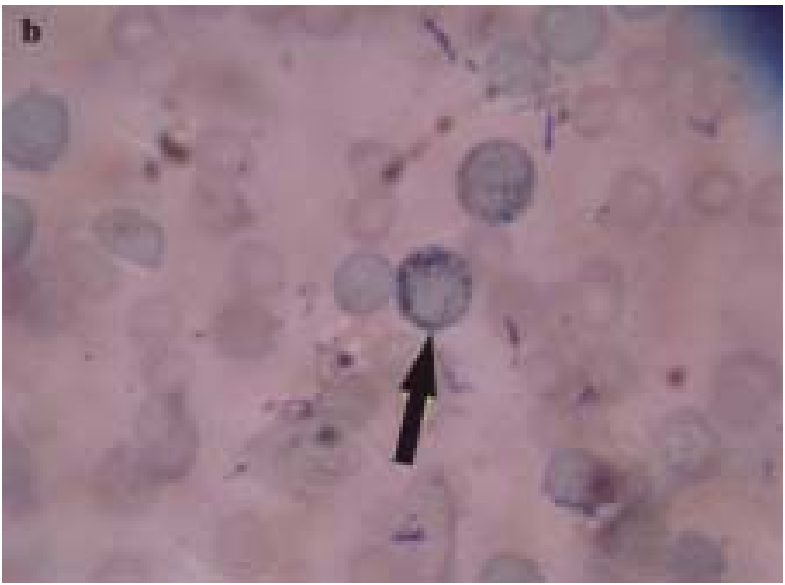

Figure 1 b.

Figure 1 a.

Figure 1.

(a) Bone marrow aspiration. Polymorphic population of blasts, with the large blasts (myeloid like) demonstrating a lower nuclear-cytoplasmic ratio (NCR), open nuclear chromatin pattern and prominent large nucleoli (arrow) in contrast to the smaller blasts with a high NCR (lymphoid like). Leishman stain $x 1000$ original magnification.

(b) Peripheral blood film. Blasts showing Sudan black B positive granules in the cytoplasm (arrow). Blasts which are negative for this stain are also seen. Sudan black B stain $\times 1000$ original magnification. 
Table 2. Scoring system for immune markers proposed by the European Group for the Immunologic Classification of Leukaemia (EGIL). $c=$ cytoplasmic, $m=$ membrane, $T d T=$ terminal deoxynucleotidyl transferase, $\mathrm{TCR}=\mathrm{T}$-cell receptor, MPO = myeloperoxidase

\begin{tabular}{llll}
\hline Score & B-lymphoid & T-lymphoid & Myeloid \\
\hline $\mathbf{2}$ & $\mathrm{cCD} 79 \mathrm{a}$ & $\mathrm{CD} 3(\mathrm{c} / \mathrm{m})$ & MPO \\
& $\mathrm{cIgM}$ & Anti-TCR & \\
& $\mathrm{cCD} 22$ & & \\
& $\mathrm{CD} 19$ & $\mathrm{CD} 2$ & $\mathrm{CD} 117$ \\
$\mathbf{1}$ & $\mathrm{CD} 20$ & $\mathrm{CD} 5$ & $\mathrm{CD} 13$ \\
& $\mathrm{CD} 10$ & $\mathrm{CD} 8$ & $\mathrm{CD} 33$ \\
& & $\mathrm{CD} 10$ & $\mathrm{CD65}$ \\
& $\mathrm{TdT}$ & $\mathrm{CD} 14$ \\
& $\mathrm{TdT}$ & $\mathrm{CD} 7$ & $\mathrm{CD} 15$ \\
& $\mathrm{CD} 24$ & $\mathrm{CD} 1 \mathrm{a} 64$ \\
\hline
\end{tabular}

\section{References}

1. Brunning RD, Matutes E, Borowitz MJ, Flandrin G, Head $\mathrm{D}$, et al. Acute leukemias of ambiguous lineage. In: Jaffe ES, Harris NL, Stein H, Vardiman JW, eds. World Health Organization Classification of Tumours. Pathology and Genetics of Tumours of Haematopoietic and Lymphoid Tissues. Lyon: IARC Press, 2001: 106-7.

2. Brunning RD, Matutes E, Harris NL, Flandrin G, Vardiman $\mathrm{J}$, et al. Acute myeloid leukaemia: introduction. In: Jaffe ES, Harris NL, Stein H, Vardiman JW, eds. World Health Organization Classification of Tumours. Pathology and Genetics of Tumours of Haematopoietic and Lymphoid Tissues. Lyon: IARC Press, 2001: 78.
3. Owaidah TM, Al Beihany A, Iqbal MA, Elkum N, Roberts GT. Cytogenetics, molecular and ultrastructural characteristics of biphenotypic acute leukaemia identified by the EGIL scoring system. Leukaemia 2006; 20: 620-6.

4. Bain BJ. Diagnosis and classification of acute leukaemia. In: Hoffbrand AV, Catovsky D, Tuddenham EGD, eds. Postgraduate Haematology. 5th ed. Oxford: Blackwell, 2005: 476-91.

5. Bene MC, Castoldi G, Knapp W, Ludwig WD, Matutes E, et al. Proposals for the immunological classification of acute leukaemias. European Group for the Immunological Characterisation of Leukaemias (EGIL). Leukaemia 1995; 9: $1783-6$. 